\title{
DEVELOPMENT AND CHARACTERIZATION OF TRANSDERMAL DELIVERY SYSTEM OF DOXAZOSIN MESYLATE
}

\author{
MADHUR KULKARNI, VISHAKHA HASTAK, SUPRIYA JADHAV
}

SCES Indira College of Pharmacy, India, 89/2A, Niramay, New Mumbai-Pune Highway, Tathawade, Pune, Maharashtra, India 411033 Email: madhur.kulkarni@indiraicp.edu.in

Received: 10 Jul 2018, Revised and Accepted: 19 Nov 2018

\begin{abstract}
Objective: The study involved development of transdermal delivery system (TDDS) of doxazosinmesylate (doxa) to achieve effective systemic delivery of the drug.

Methods: TDDS of doxa was prepared using hydroxypropyl methyl cellulose (HPMC) K100LV and polyvinyl pyrrolidone (PVP) K30 in 3:1 ratio solvent casting method. The formulation was evaluated for folding endurance, moisture uptake, $\mathrm{pH}$, drug content and in vitro permeation. Various permeation enhancers were incorporated at $5 \% \mathrm{w} / \mathrm{w}$ concentration into the patch formulationto study their impact on the drug permeation. The
\end{abstract} TDDS made with Transcutol $®$ as an enhancer was subjected to accelerated stability studies and in vivo skin irritation studies.

Results: The developed TDDS showed folding endurance of 170 , moisture uptakeof $15.7 \%$, pH of 6.3 , and drug content of $99 \pm 1.1 \%$ and $66 \%$ in vitro permeation of doxa over $24 \mathrm{~h}$. The effect of various enhancers expressed in terms of average flux can be summarized as Transcutol@ $(10.6 \pm 2.1$ $\left.\mu \mathrm{g} / \mathrm{cm}^{2} \mathrm{~h}\right)>$ dimethyl sulfoxide $\left(10.17 \pm 1.2 \mu \mathrm{g} / \mathrm{cm}^{2} \mathrm{~h}\right)>$ benzyl alcohol $\left(9.55 \pm 1.3 \mu \mathrm{g} / \mathrm{cm}^{2} \mathrm{~h}\right)>$ no enhancer $\left(8.86 \pm 1.1 \mu \mathrm{g} / \mathrm{cm}^{2} \mathrm{~h}\right)>\operatorname{dimethyl}$ isosorbide $(8.21 \pm 1.5$ $\left.\mu \mathrm{g} / \mathrm{cm}^{2} \mathrm{~h}\right)>$ Isostearic acid $\left(7.82 \pm 1.4 \mu \mathrm{g} / \mathrm{cm}^{2} \mathrm{~h}\right)>$ propylene carbonate $\left(7.67 \pm 1.4 \mu \mathrm{g} / \mathrm{cm}^{2} \mathrm{~h}\right)>$ oleic acid $\left(7.12 \mu \mathrm{g} \pm 0.8 / \mathrm{cm}^{2} \mathrm{~h}\right)$. The formulation was found to be stable during the accelerated stability studies. In vivo studies indicated absence of skin irritation effect the TDDS containing Transcutol@.

Conclusion: TDDS of doxa comprising HPMC K100LV and PVPK30 in the ratio of 3:1 and 5\% Transcutol® could serve as a potential TDDS in the treatment of benign prostatic hyperplasia (BPH) and hypertension.

Keywords: Doxazosinmesylate, Transdermal patch, Permeation enhancers, Polyvinyl pyrrolidone, Hydroxypropyl methylcellulose, Transcutol®

(C) 2019 The Authors. Published by Innovare Academic Sciences Pvt Ltd. This is an open access article under the CC BY license (http://creativecommons.org/licenses/by/4.0/) DOI: http://dx.doi.org/10.22159/ijap.2019v11i1.28414

\section{INTRODUCTION}

The transdermal route of administration is recognized as one of the potential routes for the systemic delivery of drugs. It offers many advantages over conventional oral administration such as the absence of hepatic first-pass metabolism, enhanced efficacy, lesser side effects, increased safety, reduced frequency of administration, greater convenience, and improved patient compliance. It excludes the variables that affect drug absorption from the gastrointestinal tract such as $\mathrm{pH}$, enzymatic activity and drug-food interactions. A number of marketed preparations and the studies reported in the literature indicate that this approach of drug delivery is more pertinent in the case of diseases or disorders which require longterm dosing to maintain therapeutic drug concentration and also for the ones which present untoward side effects upon oral administration [1-4]. Doxazosin mesylate (doxa) is used in the treatment of benign prostatic hyperplasia (BPH) as well as hypertension [5-7]. Its marketed preparations include oral conventional and controlled release formulations [8]. Reported studies have attempted development of orally disintegrating tablets, fast dissolving tablets, sustained release pellets and pulsatile delivery for the drug [9-12]. However, oral therapy of doxa is associated with only $65 \%$ bioavailability owing to first pass effect [13] and also with side effects like postural hypotension, dizziness, fatigue, headache, edema, and vertigo [8]. Development of a transdermal drug delivery system (TDDS) for doxa could overcome the first pass effect improving overall bioavailability and also eliminate the adverse effects. Smaller dose of 4-8 mg, the molecular weight of lesser than 600 Daltons, slight solubility in water and favorable partition coefficient of 2.1 makes doxa a suitable candidate for development of TDDS. There is enough evidence in literature wherein various anti-hypertensive drugs have been tried for the development of TDDS like metoprolol tartarate [14], nifedipine [15], amlodipine [16] and alfuzosin hydrochloride to name a few [17]. However, there is only one study that reports development TDDS of doxa where in doxa in combination with finasteride is incorporated in a gel type reservoir system constituted by poloxamer 407 and hydroxypropyl cellulose [18]. No attempt so far has been made to develop matrix type film formulation of doxa which being a solid unit dosage form offers advantages of accuracy of dose, ease of handing and overall improved convenience. Therefore, the aim of the present study was to develop TDDS of doxa using matrix type transdermal patches by solvent casting technique employing suitable polymers. The further aim of the study was to evaluate the influence of various permeation enhancers on the permeation profile of the drug.

\section{MATERIALS AND METHODS}

\section{Materials}

Doxa was obtained as a gift sample from Dr. Reddy's Laboratories, Hyderabad, India. Hydroxypropyl methyl cellulose (HPMC) K4M and K100LV, ethyl cellulose $7 \mathrm{cps}$ (EC) were obtained as gift samples from Colorcon Asia Pvt. Ltd, Mumbai, India. Polyvinyl pyrrolidone K30 (PVP K30), polyethylene glycol (PEG) 400 and glycerin were purchased from Analab Finechem Pvt. Ltd, Pune, India. Transcutol®, oleic acid, dimethyl sulfoxide, iso-stearic acid, benzyl alcohol, and dimethyl isosorbide were obtained as gift samples from Cadila Healthcare Ltd., Mumbai, India. All other chemicals used were of analytical grade.

\section{Methods}

\section{Standard plot of doxa}

Accurately weighed $10 \mathrm{mg}$ quantity of doxa was dissolved in methanol and volume was made up to $10 \mathrm{ml}$ with methanol. From the above solution, $1 \mathrm{ml}$ was withdrawn and diluted up to $100 \mathrm{ml}$ with phosphate buffer saline pH 7.4 (PBS). From this solution, suitable quantities were taken and diluted with PBS to get $2 \mu \mathrm{g} / \mathrm{ml}, 4$ $\mu \mathrm{g} / \mathrm{ml}, 6 \mu \mathrm{g} / \mathrm{ml}, 8 \mu \mathrm{g} / \mathrm{ml}, 10 \mu \mathrm{g} / \mathrm{ml}$. Absorbance was recorded at 246 $\mathrm{nm}$ against PBS as blank on a UV spectrophotometer (Shimadzu 1700 , Japan). The standard plot was obtained by plotting absorbance versus concentration. 


\section{Selection of polymer combinations for development of TDDS}

The placebo patches were prepared by solvent casting technique [19]. Various polymer combinations used are shown in table 1. Polymers were weighed accurately as per the described composition in the table and dissolved in a sufficient quantity of methanol. In each polymeric solution, glycerin $(2 \% \mathrm{w} / \mathrm{w})$, PEG $400(4 \% \mathrm{w} / \mathrm{w})$ and distilled water $(10 \% \mathrm{w} / \mathrm{w})$ were added with continuous stirring. The weight of each solution was made up of methanol. The solution was poured into a petri plate placed on the leveled surface to form a uniform layer and dried in an oven at $40^{\circ} \mathrm{C}$ to form a film. The film was then carefully removed and cut into patches of $2.5 \mathrm{~cm} \times 2.5 \mathrm{~cm}$ dimensions.

Table 1: Preparation of placebo patches using various polymer combinations

\begin{tabular}{|c|c|c|c|c|c|c|}
\hline \multirow{2}{*}{$\begin{array}{l}\text { No. } \\
1 .\end{array}$} & \multirow{2}{*}{$\begin{array}{l}\text { Polymers used } \\
\text { HPMC K100LV: PVP K30 }\end{array}$} & \multicolumn{5}{|c|}{ Compositions } \\
\hline & & $\mathrm{A}_{1}$ & $\mathrm{~A}_{2}$ & $\mathrm{~A}_{3}$ & $\mathrm{~A}_{4}$ & $\mathrm{~A}_{5}$ \\
\hline & & $3: 1$ & $2: 1$ & $1: 1$ & $1: 2$ & $2: 2$ \\
\hline \multirow[t]{2}{*}{2.} & HPMC K100 LV: EC & $\mathrm{B}_{1}$ & $\mathrm{~B}_{2}$ & $\mathrm{~B}_{3}$ & $\mathrm{~B}_{4}$ & $\mathrm{~B}_{5}$ \\
\hline & & $3: 1$ & $2: 1$ & $1: 1$ & $1: 2$ & $2: 2$ \\
\hline \multirow[t]{2}{*}{3.} & HPMC K4M: PVP K30 & $\mathrm{C}_{1}$ & $\mathrm{C}_{2}$ & $\mathrm{C}_{3}$ & $\mathrm{C}_{4}$ & $\mathrm{C}_{5}$ \\
\hline & & $3: 1$ & $2: 1$ & $1: 1$ & $1: 2$ & $2: 2$ \\
\hline \multirow[t]{2}{*}{4.} & HPMC K4M: EC & $\mathrm{D}_{1}$ & $\mathrm{D}_{2}$ & $\mathrm{D}_{3}$ & $\mathrm{D}_{4}$ & $\mathrm{D}_{5}$ \\
\hline & & $3: 1$ & $2: 1$ & $1: 1$ & $1: 2$ & $2: 2$ \\
\hline
\end{tabular}

HPMC K 100LV-hydroxypropyl methyl cellulose K 100 LV, HPMC K4M-hydroxypropyl methyl cellulose K4M, PVP K30-polyvinyl pyrrolidone K30, EC-ethyl cellulose $7 \mathrm{cps}$

\section{Evaluation of placebo patches}

The patches prepared using various polymer combinations were evaluated for following parameters [20-24].

\section{Physical appearance}

The patches were visually inspected for colour, clarity, consistency, and smoothness.

\section{Thickness}

Thickness of the patches ( 5 no.) was determined by using screw gauge and the average thickness was determined.

\section{Folding endurance}

Folding endurance was determined by repeatedly folding a patch at the centre until it broke. The number of times, the patch could be folded at the same place without breaking was recorded as folding endurance.

\section{Moisture uptake}

Pre-weighed patches (5 no.) were placed in the desiccator containing $100 \mathrm{ml}$ of saturated potassium chloride solution and kept for $24 \mathrm{~h}$. Next day, the weight of each patch was recorded. Moisture uptake was calculated using the following formula.

$$
\text { Moisture uptake }=\frac{\text { Final weight }- \text { Initial weight }}{\text { Initial weight }} \times 100
$$

\section{Moisture loss}

Pre-weighed patches (5 no.) were placed in the desiccator containing anhydrous calcium chloride. The final weight was noted after $24 \mathrm{~h}$. The moisture loss for each patch was calculated using the formula.

$$
\text { Moisture loss }=\frac{\text { Initial weight }- \text { Final weight }}{\text { Initial weight }} \times 100
$$

\section{Development of TDDS of doxa}

Based on the evaluation of placebo patches, five polymer combinations viz. $A_{1}, A_{5}, B_{1}, D_{2}$ and $D_{3}$ from table 1 were chosen for development of TDDS of doxa.

Accurately weighed amount of doxa as mentioned in table 2 was dissolved in a sufficient quantity of methanol. The solution of polymers was prepared separately in methanol using a magnetic stirrer. Weighed quantities of purified water, PEG 400 and glycerin (table 2) were added to polymer solution under stirring.

The drug solution was added at the end to the polymer solution, mixed well and the weight was made up with methanol. The solution was poured evenly in a petri plate, dried at $40^{\circ} \mathrm{C}$ in an oven over the period of $12-14 \mathrm{~h}$. The patches $(2.5 \mathrm{~cm} \mathrm{X} 2.5 \mathrm{~cm})$ of each formula were subjected to following evaluation parameters.

\begin{tabular}{|c|c|c|c|c|c|}
\hline Ingredient $(\% \mathrm{w} / \mathrm{w})$ & FA1 & FA5 & FB1 & FD2 & FD3 \\
\hline Doxa & 0.25 & 0.25 & 0.25 & 0.25 & 0.25 \\
\hline HPMC K100LV & 1.5 & 1 & 1.5 & - & - \\
\hline HPMC K4M & - & - & - & 1 & 0.5 \\
\hline PVP K 30 & 0.5 & 1 & - & - & - \\
\hline EC & - & - & 0.5 & 0.5 & 0.5 \\
\hline Glycerin & 2 & 2 & 2 & 2 & 2 \\
\hline PEG 400 & 4 & 4 & 4 & 4 & 4 \\
\hline Purified water & 10 & 10 & 10 & 10 & 10 \\
\hline Methanol & q. s 100 & q. s 100 & q. s 100 & q. s 100 & q. s 100 \\
\hline
\end{tabular}

Table 2: TDDS development of doxa

\section{Evaluation of TDDS}

The patch formulations of doxa were subjected to following evaluation parameters [20-24].

\section{pH}

The patch of every trial formula was dispersed in $10 \mathrm{ml}$ distilled water and the $\mathrm{pH}$ of the resulting suspension was measured using pH meter. (Labtronics LT 11, India).

\section{Average weight}

Patches (5 no.) of each formula were weighed individually and average weight was calculated.

\section{Drug content}

A patch was dissolved in $10 \mathrm{ml}$ of methanol by sonication for 2 min. The resulting solution was filtered, diluted suitably with PBS and absorbance was recorded spectrophotometrically at 
$246 \mathrm{~nm}$ against PBS as blank. The assay was done in triplicate for each formulation.

\section{In vitro permeation studies}

Formulations were subjected to in vitro permeation studies by using Franz diffusion cells. PBS was filled up to the brim in the receptor chamber of the cell and maintained at $37 \pm 0.5^{\circ} \mathrm{C}$ with the help of a circulating water bath. Donor compartment comprised of the patch. Donor and receptor compartments were separated by cellophane membrane with 12000 molecular weight cut off. Samples were withdrawn at $0.5,1,2,4,6,8$, and $24 \mathrm{~h}$ intervals and replaced with the equal quantity of fresh PBS. The drug content in samples was analyzed spectrophotometrically at $246 \mathrm{~nm}$ after suitable dilution with PBS. Fresh medium was replaced in the receptor compartment ensuring the absence of any air bubble between the membrane and the receptor fluid. Receptor fluid was stirred continuously throughout the study with the help of a magnetic stirrer.

\section{Formulation development with permeation enhancers}

Formulations $\mathrm{F} 1$ to $\mathrm{F} 7$ were prepared using $5 \%$ of various permeation enhancer's viz. Transcutol®, oleic acid, iso-stearic acid, benzyl alcohol, dimethyl sulfoxide, propylene carbonate and dimethyl isosorbide respectively. The basic composition and method of preparation of all these formulations was the same as that of FA1. The formulations were subjected to evaluation in a manner described under evaluation of TDDS. The values of cumulative doxa permeated obtained after in vitro skin permeation studies were fed to PCP-Disso-V 3 software to determine the flux of the drug and also the release kinetics.

\section{Accelerated stability study}

Patches were prepared as per formula F1, packed individually in aluminum foil sachets and subjected to accelerated stability studies for $3 \mathrm{mo}$ at $40 \pm 2{ }^{\circ} \mathrm{C}$ and $75 \pm 5 \% \mathrm{RH}$. The samples were withdrawn at 1,2 and 3 mo intervals and subjected to appearance, folding endurance, \% moisture absorbed, $\mathrm{pH}$, assay and in vitro skin permeation studies. Permeation profiles of the stability samples were compared by applying two way ANOVA $\left({ }^{*} \mathrm{p}<0.05\right)$ using GraphPad Prism software version 5.01.

\section{Skin irritation study}

After obtaining the approval of Institutional Animal Ethics Committee (ICP/IAEC/2017-18/03), 5 New Zealand male albino rabbits were procured from LACSMI Biofarm Pvt Ltd, Pune, India. The animals were allowed to acclamatize for the period of $7 \mathrm{~d}$. TDDS of formulation F1 was applied to the left-hand dorsal surface of the shaved intact skin of the rabbits. A placebo patch formulation prepared with the same formula as F1 but without the drug was applied in a similar manner to the right-hand dorsal surface of these 5 rabbits. The sites were occluded with gauze piece and an adhesive tape. The formulations were removed after $4 \mathrm{~h}$ of application. Skin reaction at the sites of application in the form of erythema or edema was assessed and scored as per Draize protocol at 1, 24, 48, $72 \mathrm{~h}, 7$ and $14 \mathrm{~d}[15,25]$. The scores of both test and placebo sites were compared statistically using Student's two-tailed t-test $(* \mathrm{p} \leq 0.05)$.

\section{RESULTS AND DISCUSSION}

\section{Standard plot of doxa}

The plot was found to be linear in the concentration range of $2-10 \mu \mathrm{g} / \mathrm{ml}$ at $246 \mathrm{~nm}$. Regression coefficient was found to be 0.9989 indicating the linearity of absorbance in the studied concentration range.

\section{Selection of polymer combinations for development of TDDS}

HPMC K100LV, HPMC K4M, PVP K30, and EC were used in combination as film formers and patches were prepared using various ratios of these polymers. Methanol was used as a vehicle since selected polymers, as well as doxa, showed good solubility in it. Moreover, methanol being volatile evaporatd quickly to leave behind the the polymeric film. Water, PEG 400 and glycerin were used as plasticizers to retain the integrity of the patch as well as to contribute flexibility. Patches of compositions $\mathrm{A}_{3}, \mathrm{~B}_{3}, \mathrm{C}_{3}$ very thin and fragile owing to the lower concentration of the polymers. Patches prepared using formulae $\mathrm{B}_{4}, \mathrm{~B}_{5}, \mathrm{D}_{4}, \mathrm{D}_{5}$ showed small lumps upon drying which could be attributed to the poorer solubility of EC in the selected vehicle. Combinations $\mathrm{C}_{1}, \mathrm{C}_{5}, \mathrm{D}_{1}$ containing HPMC K4M in higher proportion exhibited high viscosity and hence were difficult to pour in the plate. Hence these compositions were not taken up for further studies.

\section{Evaluation of placebo patches}

Patches of compositions $A_{1}, A_{5}, B_{1}, D_{2}$ and $D_{3}$ had acceptable clarity and appearance. The thickness of all these patches was in the range of 0.27 to $0.33 \mathrm{~mm}$. Folding endurance of the patches was found to be in the range of 144 to 170 . A higher value of folding endurance indicates a better physical strength of the patch and resistance to breaking during clinical use.

Moisture absorption test gives an indication of the physical stability of the patch at high relative humidity whereas moisture loss indicates the behavior of patch when exposed to excessively dry conditions. Both these tests help in the selection of appropriate formulation components, packaging material, and storage condition for the formulation. Moisture absorbed by various formulations was found to be in the range of 11 to $18 \%$ whereas moisture loss was found between 1.9 to $6 \%$. HPMC and PVP K30 based formulations showed higher moisture uptake as well as moisture loss as compared to that of patches $B_{1}$ and $B_{2}$. This could be attributed to the presence of EC in these compositions which inherently is less sensitive to moisture as compared to HPMC.

\section{Development of TDDS of doxa}

The compositions $A_{1}, A_{5}, B_{1}, D_{2}, D_{3}$ formed transparent, clear patches of high folding endurance and better physical stability at reasonable conditions of RH. Hence these compositions were chosen for further formulation development studies. The recommended oral extended release dose of doxa is $4 \mathrm{mg}$ once a day [8]. TDDS of doxa was hence prepared in a way that each $2.5 \mathrm{~cm} \times 2.5 \mathrm{~cm}$ patch contained doxa ( $4.85 \mathrm{mg}$ ) equivalent to $4 \mathrm{mg}$ of doxazosin free base.

\section{Evaluation of TDDS}

The results of the evaluation parameters of the TDDS are shown in table 3.

Table 3: Evaluation of TDDS of doxa

\begin{tabular}{lllll}
\hline Evaluation parameter & FA1 & FA5 & FB1 & FD2 \\
pH & 6.3 & 6.2 & 6.1 & 6.4 \\
Average weight* (mg) & $225 \pm 11$ & $223 \pm 9$ & $228 \pm 14$ & $195 \pm 12$ \\
Assay (\%)\# & $99 \pm 1.1$ & $99.1 \pm 0.6$ & $100 \pm .6$ & $155 \pm 11$ \\
\hline
\end{tabular}

*The values are mean \pm standard deviation of $n=5$ \# The values are mean \pm standard deviation of $n=3$

In vitro skin permeation study was carried out for patches of all the five formulations by using Franz diffusion cells. Permeation profiles are shown in fig. 1.

TDDS of FA1 showed maximum and that of FD3 showed minimum permeation of doxa as compared to the rest. Higher permeation from FA1 could be owing to the hydrophilic polymer matrix of lower viscosity grade allowing the higher release of drug from the formulation which in turn resulted in greater flux across the barrier membrane. Formulation FD3 contained HPMC K4M and EC. The higher viscosity of the former and the hydrophobicity of the later polymer could have retained the drug within the formulation thus affecting its permeation significantly.

Formulation FA1 was selected for further studies. 


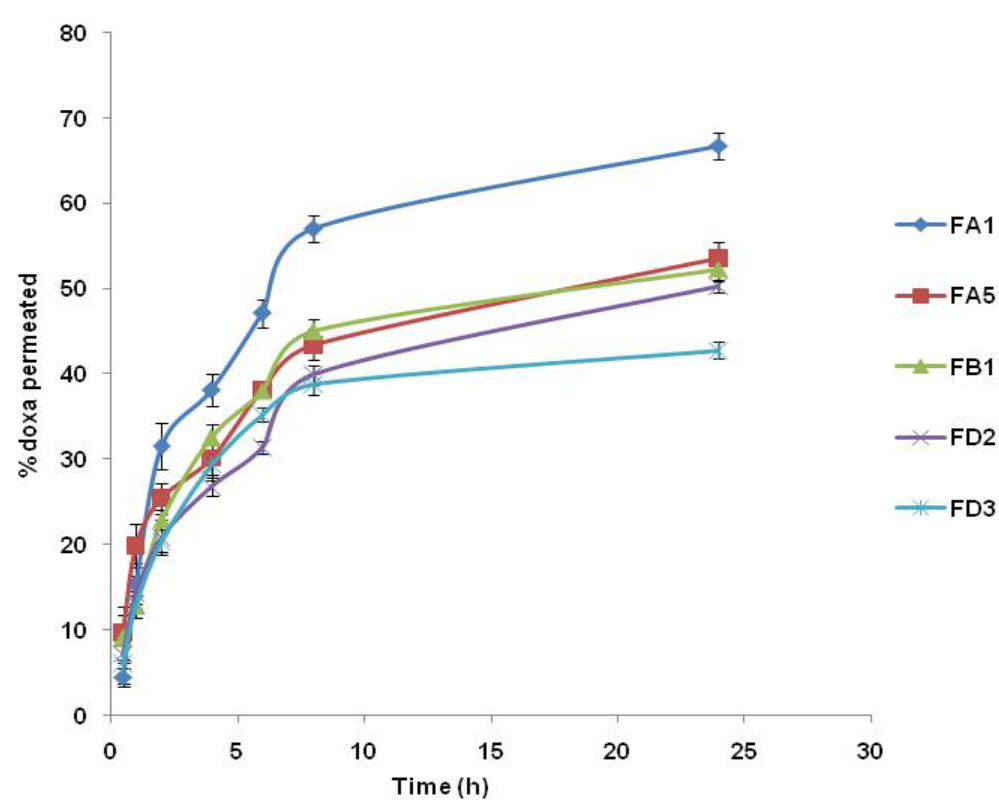

Fig. 1: In vitro permeation study of doxa fromTDDS formulations. The values are mean \pm standard deviation of $n=3$. FA1-patch made with HPMC K100 LV and PVP K 30 in 3:1 ratio, FA5-patch made with HPMC K100 LV and PVP K 30 in 2:2 ratio, FB1-patch made with HPMC K100 LV and EC in 3:1 ratio, FD2-patch made with HPMC K4M and EC in 3:1 ratio FD3-patch made with HPMC K4M and EC in 1:1 ratio

\section{Formulation development with permeation enhancers}

Permeation enhancers are used routinely in cosmetic, dermal and transdermal formulations in order to increase the rate and extent of permeation of active into or across the skin. Enhancers like Transcutol®, benzyl alcohol, dimethyl isosorbide enhance the partitioning of the drug into the skin [26, 27]. Dimethyl sulfoxide, propylene carbonate are polar, aprotic solvents which are known to extract lipids and/or keratin from the skin thereby improving the permeation. Fatty acids like oleic acid, isostearic acid fluidize the lipid bilayer by incorporating themselves into its organized structure [28]. TDDS of doxa were prepared using all these enhancers in order to evaluate their impact on its permeation.

In vitro permeation profiles of formulation, $\mathrm{FA} 1$ and $\mathrm{F} 1$ to $\mathrm{F} 7$ are depicted in fig. 2.

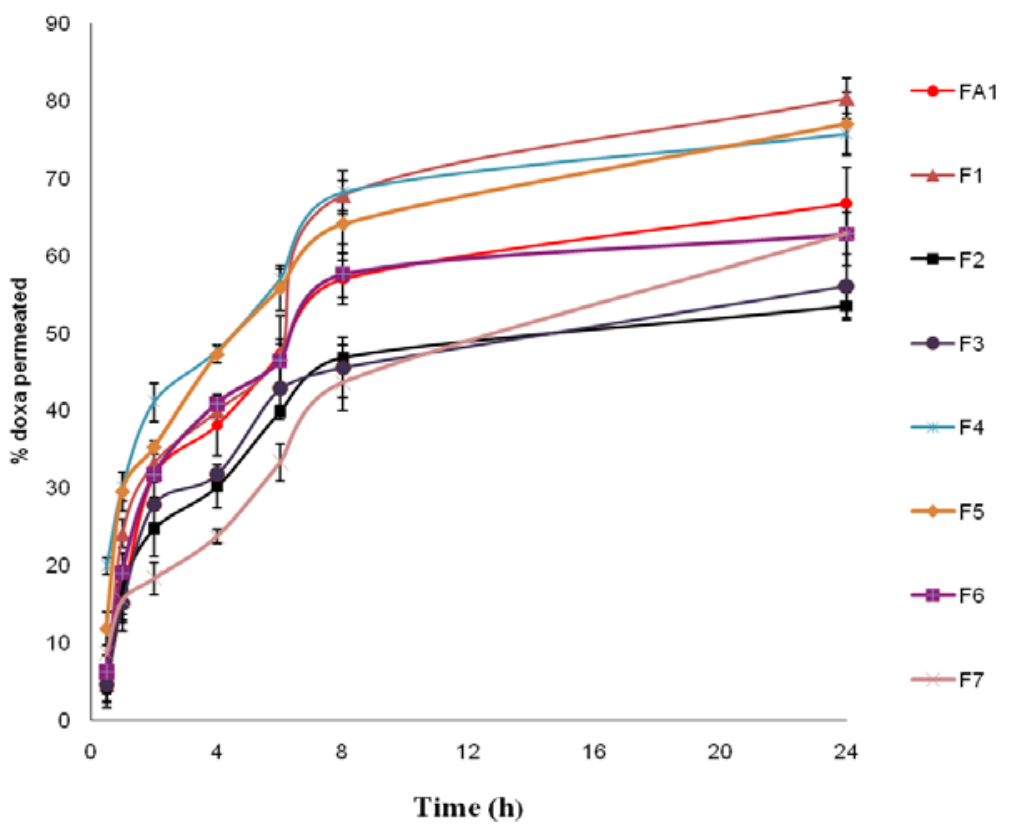

Fig. 2: In vitro permeation of doxa from TDDS containing various permeation enhancers. The values are mean \pm standard deviation of $n=3$. Key: FA1-TDDS with no enhancer, F1-with Transcutol ${ }^{\circledR}$, F2-with oleic acid, F3-with isostearic acid, F4-with benzyl alcohol, F5-with dimethyl sulfoxide, F6-with propylene carbonate, F7-with dimethyl isosorbide

Transcutol ${ }^{\circledR}$, benzyl alcohol and dimethyl sulfoxide remarkably improved the permeation of doxa as compared to the absence of enhancer in the formula FA1. The enhancement in permeation could be attributed to higher diffusion of the drug from the polymeric matrix in presence of Transcutol ${ }^{\circledR}[28,29]$. Interaction of dimethyl sulfoxide and even benzyl alcohol with lipophilic membrane could be a reason for better permeation of drug across the membrane [30]. Incorporation of oleic acid, isostearic acid, dimethyl isosorbide and 
propylene carbonate in formulations F2, F3, F6, and F7 respectively showed suppression of permeation of the drug. This could be attributed to the enhancement of solubility of the drug in the polymeric matrix in presence of either of these enhancers. Increased solubility of the drug in the formulation could have led to a reduction in thermodynamic activity of the drug, in turn, decreasing its partitioning into the membrane [29]. Transcutol $\AA$ and dimethyl sulfoxide enhanced the permeation of doxa to a greater extent. The effect of various enhancers expressed in terms of average flux can be summarized as Transcutol ${ }^{\circledR}\left(10.6 \pm 2.1 \mu \mathrm{g} / \mathrm{cm}^{2} \mathrm{~h}\right)>$ dimethyl sulfoxide $\left(10.17 \pm 1.2 \mu \mathrm{g} / \mathrm{cm}^{2} \mathrm{~h}\right)>$ benzyl alcohol $\left(9.55 \pm 1.3 \mu \mathrm{g} / \mathrm{cm}^{2} \mathrm{~h}\right)>$ no enhancer $\left(8.86 \pm 1.1 \mu \mathrm{g} / \mathrm{cm}^{2} \mathrm{~h}\right)>$ dimethyl isosorbide $\left(8.21 \pm 1.5 \mu \mathrm{g} / \mathrm{cm}^{2} \mathrm{~h}\right)$ $>$ Isostearic acid $\left(7.82 \pm 1.4 \mu \mathrm{g} / \mathrm{cm}^{2} \mathrm{~h}\right)>$ propylene carbonate $(7.67 \pm 1.4$ $\left.\mu \mathrm{g} / \mathrm{cm}^{2} \mathrm{~h}\right)>$ oleic acid $\left(7.12 \mu \mathrm{g} \pm 0.8 / \mathrm{cm}^{2} \mathrm{~h}\right)$.

Though the use of artificial lipophilic membrane helped in distinguishing the impact of enhancer on the permeation of doxa, it would be best to use the human cadaver skin to understand the exact influence of the enhancer on the flux of the drug. The actual presence of the components like lipids, ceramides, and keratin of human skin are difficult to mimic by a cellophane membrane. Moreover, though formulation F1 showed the highest value of drug permeation, there was no statistically significant difference in the flux of doxa from formulations F1, F4 and F5 containing Transcutol ${ }^{\circledR}$, benzyl alcohol and dimethyl sulfoxide respectively. Use of in vivo studies is expected to distinguish the influence of these enhancers in a better way.

In order to deduce the kinetics of in vitro permeation of drug from the eight formulations, various equations were used, such as the zero-order rate equation, which describes the systems where the release rate is independent of the concentration of the drug. The first order equation describes the release from systems where dissolution rate is dependent on the concentration of the dissolving species. The Higuchi's square root equation describes the release from systems where the drug is dispersed in a polymeric matrix, and the rate of drug release is related to the rate of drug diffusion from the matrix [31].

Permeation profiles of the TDDS showed the closest fit to Higuchi's equation as indicated by the values of correlation coefficient closest to unity. This postulated diffusion based permeation of the drug from the polymeric matrix formulations.

\section{Accelerated stability study}

The stability samples of formulatiuon F1 at 1,2 and 3 mo intervals showed acceptable appearance and folding endurance in the range of 165-170 indicating good physical stability. $\mathrm{pH}$ of the samples was between 6.2 to 6.4 and drug content in the range of 98 to $100 \%$. In vitro permeation profiles of stability samples when compared with that of the initial did not show significant difference thus confirming the robustness of the formulation at accelerated conditions of temperature and humidity.

\section{Skin irritation study}

Draize skin irritation protocol was used to study the skin irritation effect of the TDDS. Application of formulation F1 to the shaved back portion of New Zealand albino rabbits did not lead to any erythema or edema as compared to the placebo formulation which served as a control. The scores of erythema and edema calculated over the observation period of $14 \mathrm{~d}$ for test and control were zero. This confirmed the innocuous nature of the formulation and its safety in application to the skin.

\section{CONCLUSION}

TDDS of doxa formulated with HPMC K100LV and PVP K-30 in the ratio of $3: 1$ and containing either $5 \%$ Transcutol ${ }^{\circledR}, 5 \%$ dimethyl sulfoxide or $5 \%$ benzyl alcohol showed promising in vitro skin permeation profiles over a $24 \mathrm{~h}$ time period. TDDS containing Transcutol ${ }^{\circledR}$ when subjected to accelerated stability studies showed acceptable physical and chemical stability traits with no significant changes in permeation profile. In vivo skin irritation test of the formulation proved its safe, nonirritating and innocuous nature. Pharmacokinetic studies would be essential to establish the potential of developed TDDS in delivering the therapeutic concentrations of doxa for the treatment of $\mathrm{BPH}$ and hypertension.

\section{ACKNOWLEDGMENT}

Authors would like to acknowledge Dr. Reddy's Laboratories, Hyderabad, Cadila Healthcare Ltd., Mumbai for the gift samples of doxa and all the permeation enhancers respectively.

\section{AUTHORS CONTRIBUTIONS}

All authors have contributed equally to the present work and manuscript preparation

\section{CONFLICT OF INTERESTS}

Authors declare no conflict of interest

\section{REFERENCES}

1. Walters KA, Brain KR. Topical and transdermal delivery. In: Gibson M. editor. Pharmaceutical preformulation and formulation. 2nd ed. New York: Informa Healthcare Inc; 2009. p. 475.

2. Tanwar H, Sachdeva R. Transdermal drug delivery system: a review. Int J Pharm Sci Res 2016;7:2274-90.

3. Ravichandran V, Manivannan S. Wound healing potential of transdermal patches containing bioactive fraction from the bark of Ficus racemosa. Int J Pharm Pharm Sci 2016;6:326-32.

4. Jhawat V, Saini V, Kamboj S, Maggon N. Transdermal drug delivery systems: approaches and advancement in drug absorption through skin. Int J Pharm Sci Rev Res 2013;20:4756.

5. Wilt TJ, MacDonald R. Doxazosin in the treatment of benign prostatic hypertrophy: an update. Clin Interv Aging 2006;1:389-401.

6. Sweetman SC. Martindale: the complete drug references. 34th ed. London: Pharmaceutical Press; 2005. p. 908-9.

7. Wolak T, Toledano R, Novack V, Sharon A, Shalev A, Wolak A. Doxazosin to treat hypertension: It's time to take it personallya retrospective analysis of 19495 patients. J Hypertens 2014;32:1132-7.

8. Current Index of Medical Specialities; Bengaluru (India): CIMS Medica India; 2017. p. 230.

9. Chaudhari SP, Kotian NR. Formulation development and evaluation of orally disintegrating tablets of doxazosinmesylate. Asian J Pharm 2012;6:266-74.

10. Preethi GB, Banerjee S, Shivakumar HN, Ravi Kumar M. Formulation of fast dissolving tablets of doxazosin mesylate drug by direct compression method. Int J Appl Pharm 2017;9:22-8.

11. Kim Ju HJ, Oh T, Rhee Y, Chi S, Park E. Preparation and evaluation of sustained release doxazosin mesylate pellets. Chem Pharm Bull 2013;61:371-8.

12. Lin HL, Lin SY, Lin YK, Lo YW, Sheu MT. Release characteristics and in vitro-in vivo correlation of pulsatile pattern for a pulsatile drug delivery system activated by membrane rupture via osmotic pressure swelling. Eur J Pharm Biopharm 2008;70:289-301.

13. Elliot HL, Meredith PA, Reid JL. Pharmacokinetic overview of doxazosin. Am J Cardiol 1987;59:784-814.

14. Bharkatiya M, Nemal RK. Development and characterization of transdermal patches of metoprololtartrate. Asian J Pharm Clin Res 2010;3:130-4.

15. Raj A. Formulation evaluation and in vitro permeation studies of transdermal nifedipine from matrix type patches. Int J Pharm Pharm Sci 2014;6:185-8.

16. Lincy J, Kumar A. Comparison of amlodipine transdermal patches using HPMC and chitosan. Asian J Pharm Clin Res 2014;7:86-90.

17. Prasanthi D, Lakshmi PK. The effects of chemical enhancers in transdermal penetration of alfuzosin hydrochloride. ISRN Pharm 2012;12:55-9.

18. Pupe CG, Do Carmo FA, De souse VP. Development of a doxazosin and finasteride transdermal system for combination therapy of benign prostatic hyperplasia. J Pharm Sci 2013;102:4057-64. 
19. Kumar M, Trivedi V, Shukla A, Dev SK. Effect of polymers on the physicochemical and drug release properties of transdermal patches of atenolol. Int J Appl Pharm 2018;4:68-73.

20. Das SP, Saha P. Design and characterization of transdermal patches of phenformin hydrochloride. Int J Curr Pharm Res 2017;6:90-3.

21. Patel DS, Patel MV, Patel KM, Patel BA, Patel PA. Transdermal patches: a complete review on transdermal drug delivery system. Int J Pharm Sci Res 2012;1:62-78.

22. Bathe R, Kapoor R. Transdermal drug delivery system: formulation, development and evaluation-an overview. Int J Biomed Adv Res 2015;6:1-10.

23. Fayez SM, Gad S, Ghorab MM. Formulation and evaluation of etodolac lecithin organogel transdermal drug delivery systems. Int J Pharm Sci Res 2015;7:325-34.

24. Van Buskirk GA, Gonzalez MA, Shah VP, Barnhardt S, Barrett C. Scale-up of adhesive transdermal drug delivery systems. Pharm Res 1997;14:848-52.

25. Draize JH, Woodard GM, Calvery HO. Methods for the study of irritation and toxicity of substances applied topically to the skin and mucous membranes. J Pharmacol Exp Ther 1944;82:377-90.

26. Nanayakkava GR, Bartlett A. The effects of unsaturated fatty acids in benzyl alcohol on the percutaneous permeation of three model penetrants. Int J Pharm 2005;301:129-39.

27. Squillante E, Maniar A, Needham T. Codiffusion of propylene glycol and dimethyl isosorbide in hairless mouse skin. Eur J Pharm Biopharm 2000;46:265-71.

28. Karande P, Mitragotri S. Enhancement of transdermal drug delivery via synergistic actions of chemicals. Biochim Biophysica Acta 2009;1788:2362-73.

29. Saini S, Chauhan SB, Agarwal SS. Recent development in penetration enhancers and techniques in transdermal drug delivery system. J Adv Pharm Educ Res 2014;4:31-40.

30. Abdelgawad R, Nasr M, Hamza YM, Awa GA. Topical and systemic dermal carriers for psoriasis. Int J Curr Pharm Res 2015;1:4-9.

31. Siepmann J, Peppas NA. Modelling of drug release from delivery systems based on hydroxypropyl methyl cellulose (HPMC). Adv Drug Delivery Rev 2001;48:139-57. 